\title{
On the Mechanism of Stress Corrosion Cracking in Austenitic Stainless Steels
}

\author{
By Michinori Takano* and Saburo Shimodaira*
}

\begin{abstract}
Stress corrosion behaviours of austenitic stainless steels containing various contents of nitrogen and of Inconel were investigated using thin-foil and bulk specimens.

The mode of micro-attack in thin-foil specimens of nitrogen-rich stainless steel in a $3 \% \mathrm{NaCl}$ aqueous solution (pH 1.6 ) at room temperature and of Inconel in a boiling $42 \% \mathrm{MgCl}_{2}$ aqueous solution was almost the same as that for nitrogen-rich stainless steel in a boiling $42 \% \mathrm{MgCl}_{2}$ aqueous solution. Stress corrosion behaviours of bulk specimens observed by the replica technique indicated that at the initial stage of corrosion no difference was recognized in the nucleation of microattack in all the cases, but with increase in exposure time there appeared a remarkable difference in the corrosion behaviours depending on the relative difficulty of the cracking conditions. In a nitrogen-rich stainless steel aged at $200^{\circ} \mathrm{C}$ after deformation, the segregation and precipitation were recognized in both the transmission electron microscope observations and the constant strain rate stress-strain relations.

From these results, it seems that the segregation of solute atoms is particularly necessary for the propagation of stress corrosion cracking in austenitic stainless steels, and that the nucleation and propagation of cracking have different mechanisms.
\end{abstract}

(Received May 11, 1966)

\section{Introduction}

On the mechanism of stress corrosion cracking of alloys in a corrosive environment, there exist two principal hypotheses : One assumes an entirely electrochemical process and the other alternative electrochemical and mechanical processes. An important advance in this field has recently been done by the transmission electron microscope technique with thin-foil specimens, but very little is known about the detailed mechanism.

Using thin-foil specimens, Bassett and Edeleanu(1) observed the formation of pits in $\mathrm{Cu}-\mathrm{Zn}$ alloy in an anmmonia aqueous solution, but they could not clearly show the relationship between imperfections in crystal and pitting corrosion. With the advancement of investigation by direct observation of crystallographic defects, it has been proved that preferential corrosion of these defects in the stress corrosion environments plays an important role in the occurrence of transgranular cracking ${ }^{(2) \sim(5)}$. In a previous paper on the initiation of stress corrosion cracking in austenitic stainless steels the following results are reported ${ }^{(6)}$ :

1. Dislocations distribute in a planar arrangement.

2. Only slip steps which are formed continuously under an applied stress in a corrosive environment react as the active sites.

The nucleation of transgranular stress corrosion cracking of austenitic stainless steels would require the abovementioned two conditions. However, the investigation

* The Research Institue for Iron, Steel and Other Metals, Tohoku University, Sendai Japan.

(1) G. A. Bassett and C. Edeleanu: Rhysical Melallurgy of Stress Corrosion Fracture, p. 117, Interscience, New York, (1959).

(2) D. A. Vaughan, D. I. Phalen, C. L. Peterson and W.K. Boyd: Corrosion, 19 (1963), 315 t.

(3) H. W. Pickering and P. R. Swann: Corrosion, 19 (1963), $373 \mathrm{t}$.

(4) D. Tromans and J. Nutting: Corrosion, 21 (1965), 143.

(5) M. R. Louthan: Corrosion, 21 (1965), 288.

(6) M. Takano and S. Shimodaira: J. Japan Inst. Metals, 29 (1965), 553. by the direct observation of corrosion using thin-foil specimens has not hitherto been successful to give any sufficient explanation about the mechanism of crack propagation and the high resistance to chloride cracking of Inconel in which the dislocations have a tendency to form a planar distribution.

In the present study, the corrosion of crystallographic imperfections was examined using thin-foil specimens of austenitic stainless steels and Inconel, and stress corrosion was also examined as a function of exposure time by the replica technique. Furthermore, the segregation and precipitation of alloying elements were investigated by means of a transmission electron microscope and an Instron tensile test machine, and the mechanisms of initiation and propagation of stress corrosion cracking were discussed.

\section{Experimental Procedures}

Stainless steels were melted in the induction electric furnace in argon atmosphere using high purity alumina crucibles. Electrolytic iron, electrolytic chromium, electrolytic nickel and nitrided ferrochromium were used as starting materials. Fabrication of the ingots was performed by hot forging, and subsequently by coldrolling to a $2.0 \mathrm{~mm}$ strip. A sheet (1.5 $\mathrm{mm}$ in thickness) of commercial Inconel was used. The chemical compositions of specimens are listed in Table 1. The specimens for transmission electron microscopy were prepared by the following method : Each alloy was cold rolled to a sheet $0.1 \mathrm{~mm}$ in thickness, followed by vacuum annealing at $1050^{\circ} \mathrm{C}$ and electropolishing. The application of stress to these thin-foil specimens in a corrosive environment was performed in the same way as in a previous report ${ }^{(6)}$. The stainless steels and Inconel were cut into the sizes of $60 \times 6.5 \times 2.0 \mathrm{~mm}$ and $60 \times 6.5 \times 1.5 \mathrm{~mm}$, respectively, and annealed at $1050^{\circ} \mathrm{C}$ in vacuum for the observation of stress corrosion of bulk specimens by the replica method. The 3-point bend-beam system was used 
Table 1 Chemical compositions of test alloys.

\begin{tabular}{c|c|c|c|c|c|c|c}
\hline & C & Cr & Ni & N & Fe & Mn & Si \\
\hline Steel A & 0.006 & 17.02 & 10.20 & 0.011 & $\mathbf{R}$ & - & - \\
Steel B & 0.009 & 17.18 & 9.92 & 0.22 & $\mathbf{R}$ & - & - \\
Steel C & 0.13 & 18.09 & 8.08 & 0.053 & $\mathbf{R}$ & - & - \\
Inconel & 0.04 & 16.07 & 72.09 & - & 9.99 & 1.00 & 0.72 \\
\hline
\end{tabular}

Table 2 Solutions used for the corrosion tests of thin-foil and bulk specimens.

\begin{tabular}{c|c|c}
\hline Alloy & $\begin{array}{c}\text { Boiling 42\% } \mathrm{MgCl}_{2} \\
\text { aqueous solution } \\
\text { (Solution B) }\end{array}$ & $\begin{array}{c}3 \% \text { NaCl aqueous } \\
\text { solution at r. t. } \\
\text { (pH 1.6) } \\
\text { (Solution A) }\end{array}$ \\
\hline $\begin{array}{c}\text { Steel A } \\
\text { Steel B } \\
\text { Inconel }\end{array}$ & $\begin{array}{c}\text { bulk } \\
\text { thin-foil* and bulk } \\
\text { thin-foil and bulk }\end{array}$ & $\begin{array}{c}\text { bulk } \\
\text { thin-foil and bulk }\end{array}$ \\
\hline
\end{tabular}

$*$ ref. $(6)$

for the deformation of the bulk specimens. Solutions used as corrosives are shown in Table 2.

\section{Results and Discussion}

\section{Stress corrosion behaviours in thin-foil specimens}

Dislocation distributions of $5 \%$ deformed alloys are shown in Photo. 1. In Steel A containing less carbon
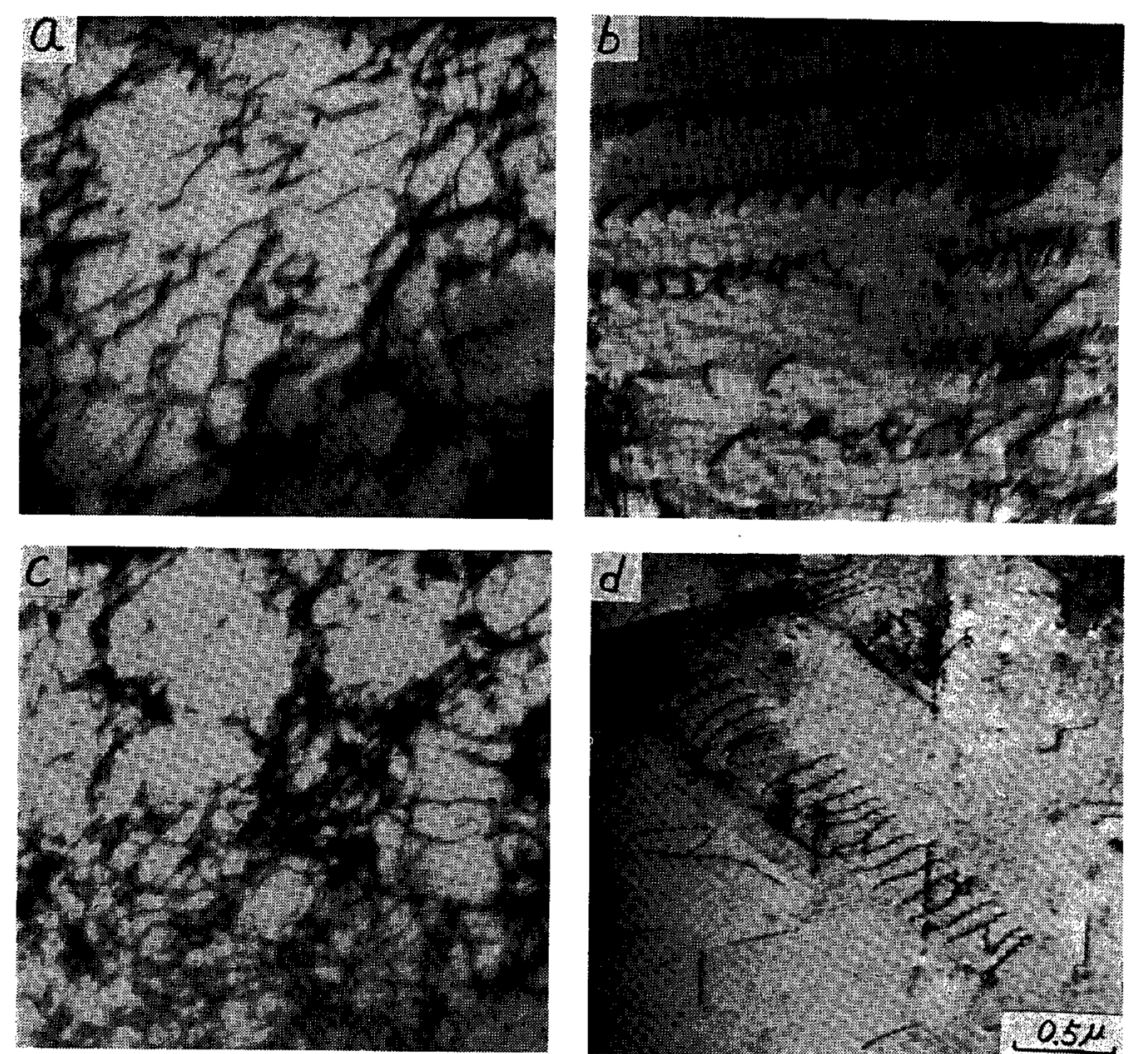

Photo. 1 Transmission electron micrographs of 5 percent deformed Steel A (a), Steel B (b), Steel C (c) and Inconel (d).

and nitrogen than that of commercial alloys, the dislocations are not constrained to particular slip planes and tend to form a cellular distribution (Photo. 1 (a)). In Steel B containing $0.22 \%$ nitrogen, the slips are restricted to particular planes and the dislocations form a

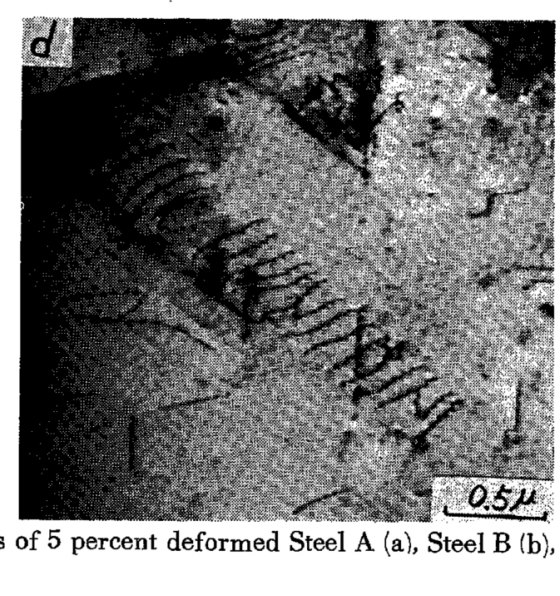

planar distribution (Photo. 1 (b)), and in Steel C containing $0.13 \%$ carbon, cross slips are liable to occur and thereby dislocations form a cellular distribution. (Photo. 1 (c)). Dislocation arrangements of Inconel which containing a large amount of nickel and have a high stacking fault energy ${ }^{(7)}$ show a planar distribution (Photo. 1 (d)).

The relationship between stress corrosion susceptibility and dislocation distributions in austenitic stainless steels has already been made clear ${ }^{(6) \sim(8)}$; the steels having a dislocation distribution of the planar arrangement are susceptible to cracking. In Inconel, however, the dislocations form a planar distribution, but being resistant to chloride cracking ${ }^{(9)}$.

The corrosion of the thin-foil specimens of Steel B and Inconel, which revealed a planar dislocation arrangement as shown in Photos. 1 (b) and (d), were investigated in a $3 \% \mathrm{NaCl}$ aqueous solution ( $\mathrm{pH} \mathrm{1.6)} \mathrm{(solution} \mathrm{A)} \mathrm{at}$ room temperature for Steel B and in a boiling $42 \%$ $\mathrm{MgCl}_{2}$ aqueous solution (solution $\mathrm{B}$ ) for Inconel, respectively. Traces of the preferential micro-attack obtained for Steel B in the solution A and for Inconel in the solution $B$ are shown in Photo. 2 (a) and in Photo. 2 (b) respectively. Photo. 2 indicates that the observed pits result from preferential corrosion along the slip steps caused by the dislocation movement under stress. These pitting traces are similar to those of Steel B which was elongated in the solution $B$ for $3 \min ^{(6)}$. It has been

well known that Steel B in the solution B was under the condition susceptible to stress corrosion cracking and

(7) P. R. Swann : Corrosion, 19 (1963), 102

(8) R. Stickler and S. Barnartt: J. Electrochem. Soc., 109 (1962), 343.

(9) H. R. Copson : refer (1), p. 247. 
Steel B in the solution A and Inconel in the solution B were under the condition unsusceptible to stress corrosion cracking. However, no difference could be recognized in these three cases.

From these results, it can not be considered as a suf-

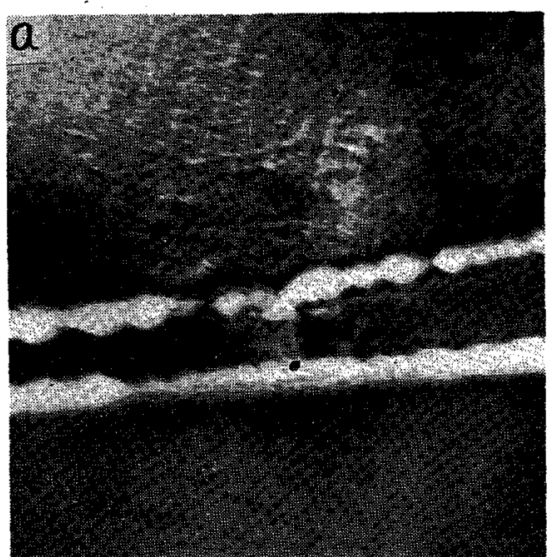

sion traces of Inconel in the solution $\mathrm{B}$ are shown in Photo. 4, and those of Steel A and Steel B in the solution $A$ are also shown in Photos. 5 (a) and (b), respectively, Photo. 6 (a) and Photo. 6 (b) show the corrosion traces of Steel A and Steel B in the solution B, respectively.

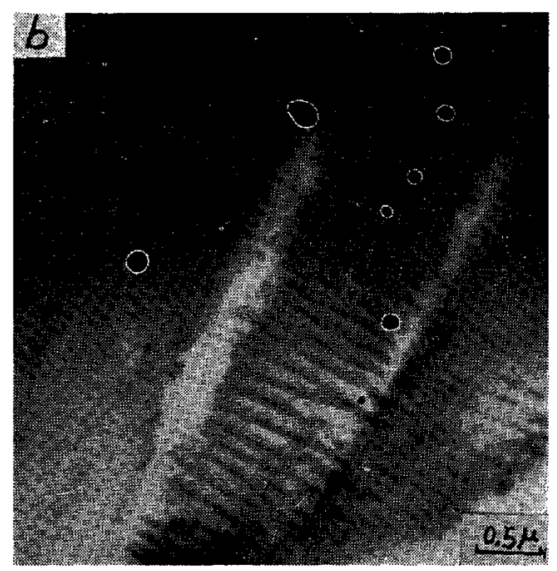

Photo. 2 Chemical micreattack at fresh slip steps observed in deformed specimens kept for $3 \mathrm{~min}$ in a corrosive environment ;

(a) steel B in solution A; (b) Inconel in solution B.

ficient condition for the propagation of stress corrosion cracking that coarse slip steps are produced on the surface of alloys under stress in a corrosive environment and preferential micro-pits occur along these regions. The above-mentioned preferential corrosion along fresh slip steps can be controlled by $\mathrm{pH}$, ion species, temperature, etc. The preferential dissolution"at fresh slip steps shown in Photo. 2 is a necessary condition for the nucleation of transgranular cracking of austenitic stainless 'steels, but not a sufficient condition for crack propagation.

\section{Stress corrosion behaviours of bulk specimens}

In the corrosion of thin-foil specimens, it is difficult to realize the three-dimensional extension of corrosion. It is extremely important to examine how the pits are

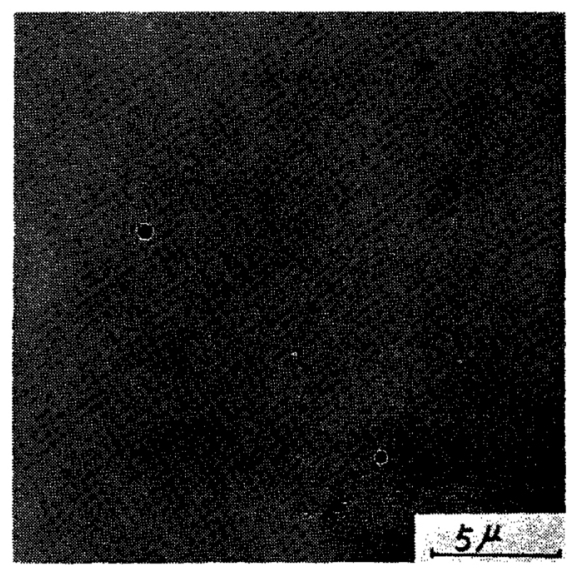

Photo. 3 Electropolished surface of a bulk specimen prior to the stress corrosion test.
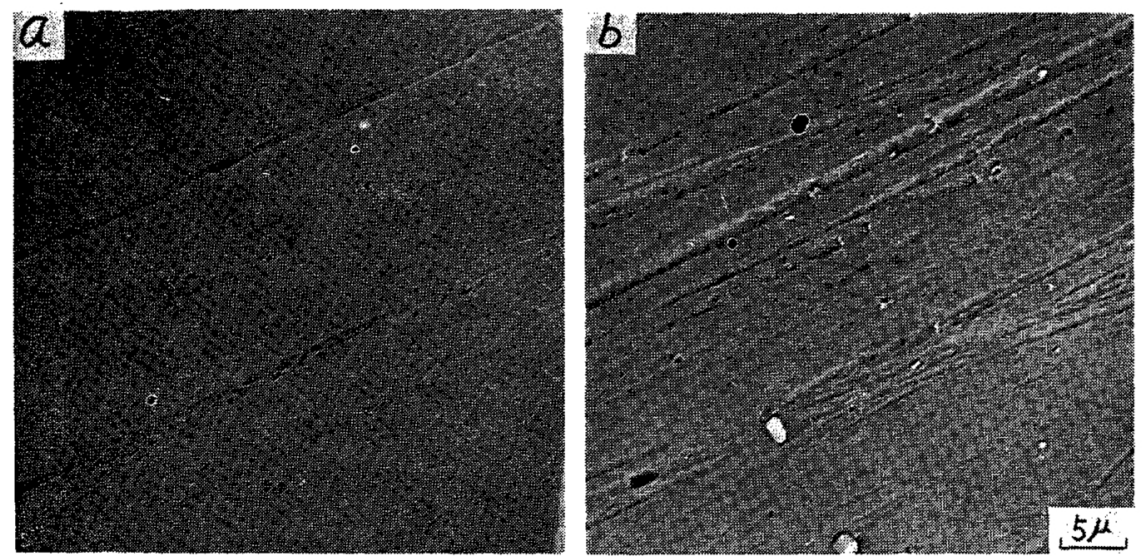

Photo. 4 Corrosion traces of Inconel after the stress corrosion test in solution B,

(a) for $5 \mathrm{~min}$ and (b) for $25 \mathrm{hr}$.

nucleated in the regions of crystallographic defects and penetrate into the interiors of the bulk specimens. Corrosion behaviours of the bulk surface, therefore, were examined as the function of time by the replica technique.

The electropolished surface of a bulk specimen prior to the stress corrosion test is shown in Photo. 3. Corro-
Photo. 4 and Photo. 5 indicate that, under a condition difficult to cause cracking such as Inconel in the solution $\mathrm{B}$ and stainless steels in the solution $\mathrm{A}$ at room temperature, the initial micro-pits on the slip steps hardly grow and cracking does not occur. On the other hand, in stainless steels treated in the solution B as shown in 

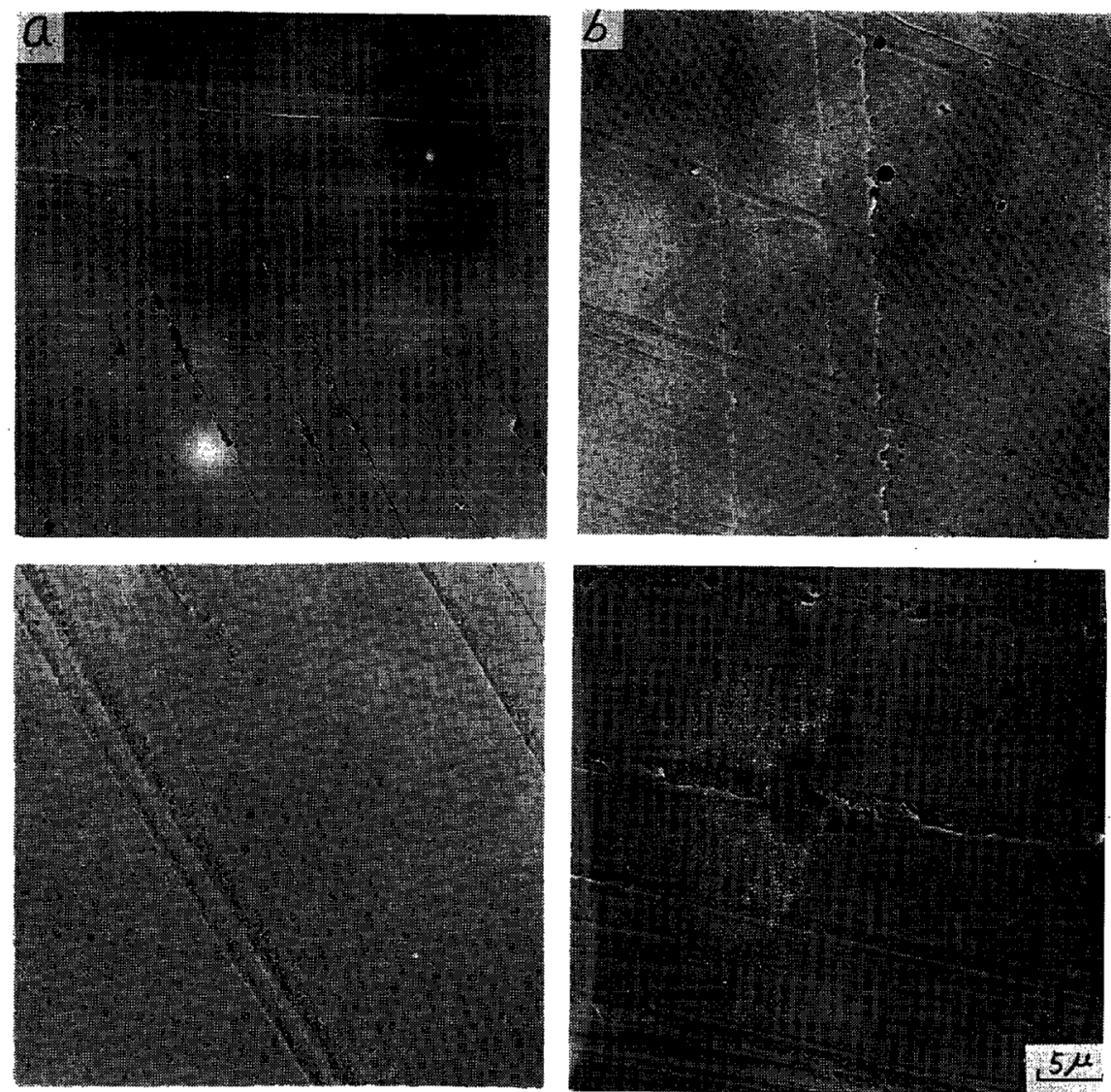

Photo. 5 Corrosion traces of (a) Steel A and (b) Steel B after the stress corrosion test in solution A. Upper : for $5 \mathrm{~min}$. Lower : for $2 \mathrm{hr}$.
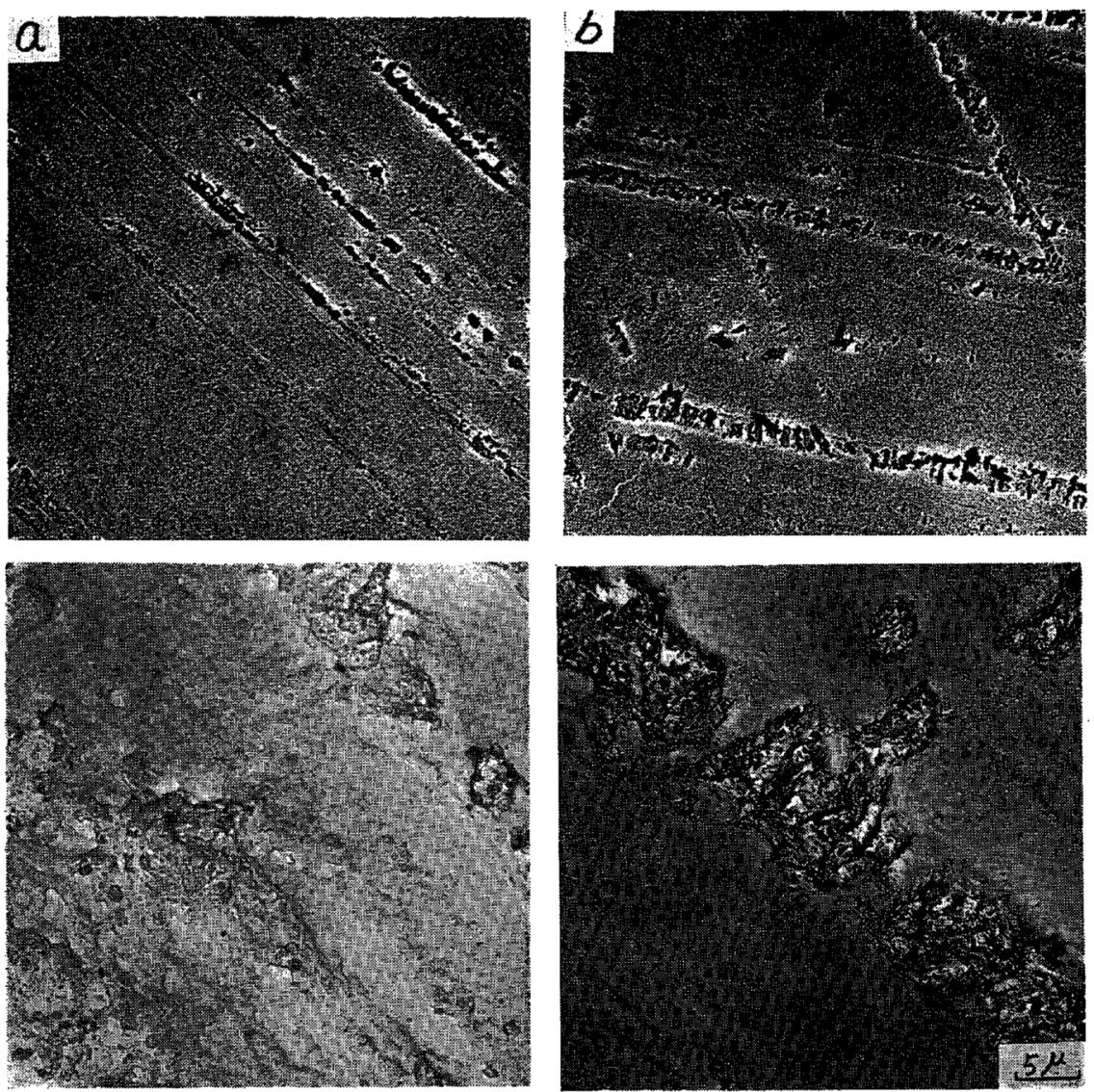

Photo. 6 Corrosion traces of (a) Steel A and (b) Steel B after the stress corrosion test in solution B. Upper : for $5 \mathrm{~min}$. Lower : for $24 \mathrm{hr}$. 
Photo. 6, the nucleated corrosion trenches proceed into the interiors of the bulk specimens with increase in exposure time, suggesting the occurrence of transgranular cracking. In this case, corrosion along the constraint slip planes in Steel B are particularly remarkable, but in Steel A, with increasing exposure time, corrosion progress into the bulk is suppressed and the micro-attack along original slip steps shows a trend to extend over the bulk surface.

The difference between the corrosion behaviours of Steel A and Steel B in the solution B can be attributed to their characteristic dislocation distributions in the alloys, and seems to depend largely on the segregation of solute atoms associated with their dislocation arrangements.

Although Steel A shows a tangling dislocation distribution, the corrosion initiates at the constraint slip steps in both solutions A and B. As the slips remarkably occur at angle of $45^{\circ}$ against the direction of applied stress, the corrosion nucleates on these slip steps.

Bulk specimens were corroded in the solution B at $154^{\circ} \mathrm{C}$ as shown in Photo. 6. Swann and Pickering (10), and Uhlig and Sava(11) pointed out that segregation of solute atoms in such bulk specimens might be possible at this temperature. Therefore, chemical compositions in the vicinity of the coarse slip planes would be different from those in the surrounding regions, and the corrosion extends into the interior of the bulk specimen along slip planes by electrochemical attack.

In Steel A containing a smaller amount of solute atoms than that of Steel B, the segregation of solute atoms is of course possible, but the sites where solute atoms atoms in the Inconel do not segregate or even if the segregation occurs at a given temperature, these segregated regions are low in chemical activity in the solution B. In the case of Photo. 5, it can be houghtt that the probability of segregation in stainless steels at room temperature is generally very small (this corresponds. to stress-strain curves in section (3)), and the initial micro-attack, therefore, would not proceed into the interior of the bulk with the exposure time.

\section{Probability of segregation}

In order to investigate the segregation of solute atoms which plays an important role in crack propagation, $2 \%$ elongated stainless steels were aged at $200^{\circ} \mathrm{C}$.

Electron micrographs of Steel B aged for $34 \mathrm{hr}$ are shown in Photos. 7 (a) and (b). Photo. 7 (b) was obtained by tilting the same region as in the Photo. 7(a). If these contrast effects are associated with an array of closely spaced dislocation dipoles as shown by Swann and Louat ${ }^{(12)}$, two dislocation groups are expected to be seen separately by tilting. In Photo. 7 any contrast which represents dislocation dipole clusters, however, is not seen even by tiltng. The contrasts seen in Photo. 7, therefore, may ke attributed to moire fringes associated with the segregation of solute atoms such as nitrogen, as reported by Swann and Nutting ${ }^{(13)}$.

Photo. 8 is a micrograph of Steel B aged at $200^{\circ} \mathrm{C}$ for $34 \mathrm{hr}$. The occurrence of precipitates which are considered to be nitrides is seen along the slip planes. A similar micrograph which might be associated with such a precipitation was also obtained from Steel B aged at $200^{\circ} \mathrm{C}$ for $200 \mathrm{hr}$. Aswegen et al. ${ }^{(14)}$ reported the
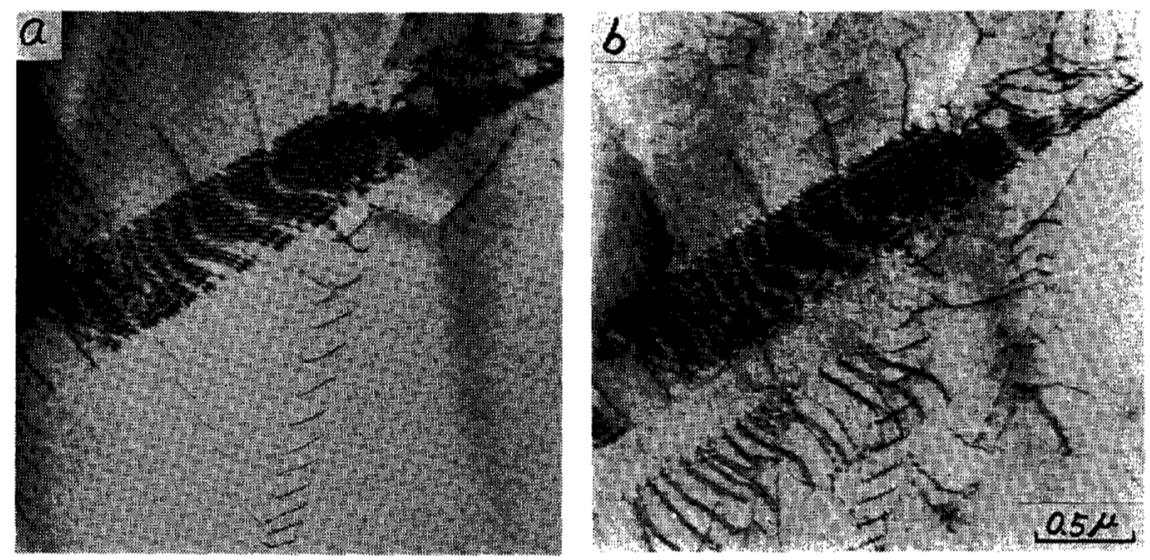

Photo. 7 Steel B deformed 2 percent and aged for $34 \mathrm{hr}$ at $200^{\circ} \mathrm{C}$.

(a) showing moiré contrast; (b) the same area as (a) but tilted.

segregate may be more extended and numerous than that in Steel B because Steel A forms a cellular dislocation distribution. The micro-attack nucleated along the slip steps, therefore, tends to extend over the surface with increasing exposure time, and the advance of corrosion into the interior of the bulk specimen is retarded.

In cases where stress corrosion cracking is difficult as seen in Photo. 4 and Photo. 5, the initial corrosion trenches do not proceed so remarkably with exposure time as seen in Photo. 6. Photo. 4 suggests that the solute

(10) P. R. Swann and H. W. Pickering : Corrosion, 19(1963), $369 \mathrm{t}$

(11) H. H. Uhlig and J. P. Sava : Corrosion Sci., 5(1965), 291. occurrence of precipitation and segregation at stacking faults in an aged stainless steel containing niobium, and Douglass et al. ${ }^{(15)}$ confirmed the preferential precipitation of nitride on the slip planes in an aged stainless steel containing nitrogen. Swann and Pickering(10), and Uhlig and Save(11) reported the possibility of solute atom segregation in austenitic stainless steels. In this

(12) P. R. Swann and N. Louat: J. Inst. Met., 91 (1963), 24.3.

(13) P. R. Swann and J. Nutting: J. Inst. Met., 90 (1961 62), 133.

(14) J.S.T. Van Aswegen, R. W. K. Honeycombe and D. H. Warrington: Acta Met., 12 (1964), 1.

(15) D. L. Douglass, G. Thomas and H. R. Roser : Corrosion, 20 (1964), 15t. 
study, behaviours of solute atoms in bulk specimens were investigated by using a TT-CM-L type Instron tensile test machine. Fig. 1 shows stress-strain relationships on Steel A, Steel B and Steel C which were elongated at $200^{\circ} \mathrm{C}$ with a constant strain rate of 0.05

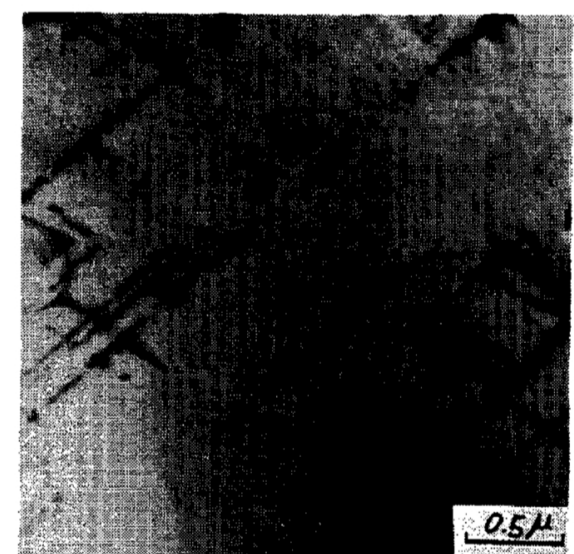

Photo. 8 Steel B deformed 2 percents and aged for $34 \mathrm{hr}$ at $200^{\circ} \mathrm{C}$. Precipitation can be seen along the slip planes.

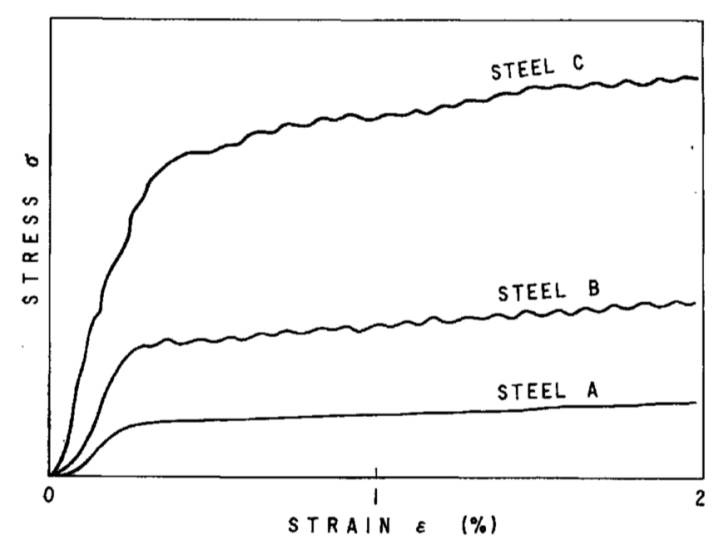

Fig. 1 Stress-strain curves in various steels at $200^{\circ} \mathrm{C}$ with the $0.05 \% / \mathrm{min}$ strain rate.

$\%$ /min in air.

For Steel B and Steel C containing large amounts of nitrogen and carbon, respectively, remarkable steps are seen in the $\sigma-\varepsilon$ curves, but for Steel A containing small amounts of nitrogen and carbon, this phenomenon can be detected to a slight degree. These steps seen in the $\sigma-\varepsilon$ curves may be attributed to the interaction of solute atoms and crystallographic imperfections ${ }^{(10)}$.

As shown in Fig. 2, in contrast with the $\sigma-\varepsilon$ curves of Steel B obtained at $200^{\circ} \mathrm{C}$, the steps in the $\sigma-\varepsilon$ curves cannot be seen at room temperature. This result is in good agreement with that of Uhlig and Sava(11); that is, the segregation of solute atoms would take place about at $200^{\circ} \mathrm{C}$. No difference in electron microscope observation, however, is recognized between those elongated $5 \%$ at room temperature and $200^{\circ} \mathrm{C}$ with the same constant strain rate of $0.05 \% / \mathrm{min}$ in air.

From these results, it is deduced that the solute atoms participating in the propagation of stress corrosion, which are hardly detected by electron microscopy, are segregated in the vicinity of slip planes, and the segregation in such a degree may be sufficient to accelerate an electrochemical reaction. This process is considered to belong to a so-called mechanochemical reaction.

The segregation is also possible for Steel $\mathrm{C}$ as seen in Fig. 1, but it is well known that the stainless steel

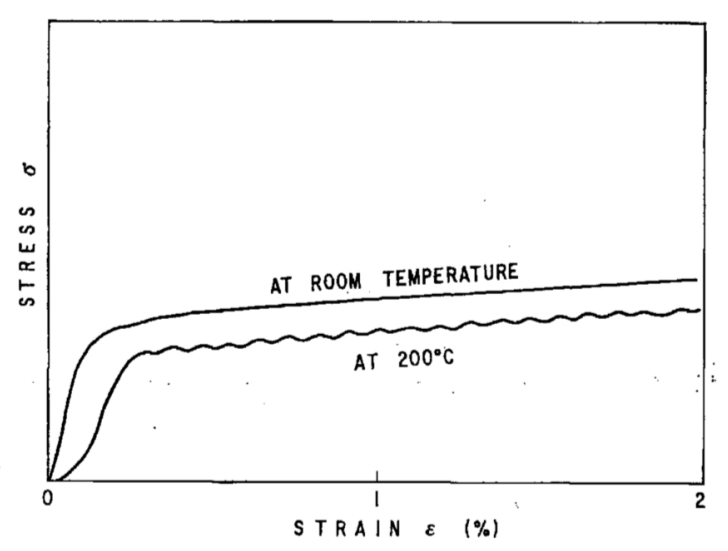

Fig. 2 Effect of temperature on stress-strain curves of Steel B. Strain rate : $0.05 \% / \mathrm{min}$.

containing a large amount of carbon, like Steel C, is resistant to cracking. This may be associated with the mode of dislocation distribution, and in carbon-rich steels such as Steel C the dislocations have a tendency to form a cellular structure. That is, the chemically active sites in a steel with a cellular dislocation distribution are uniformly distributed with a higher density than in alloys with a planar dislocation distribution, and the precipitation of carbides also occurs in grain boundaries, causing intergranular corrosion.

From the results of electron microscope observations and Instron tensile tests, the stress corrosion cracking of austenitic stainless steel would be nucleated and propagated if the following conditions are satisfied :

(1) The dislocations form a planar structure.

(2) Only the fresh slip steps are chemically active and are attacked preferentially in a corrosive environment.

(3) During the growth of particular slip steps in plastic deformation, solute atoms are segregated on the slip planes by the movement of dislocations and by the formation of vacancies which accerelate the diffusion process.

(4) The segregated regions are electrochemically active against the surrounding matrix in a corrosive environment.

When the above-mentioned conditions are satisfied, transgranular stress corrosion cracking seems to proceed by an electrochemical reaction along the segregated regions ( $\{111\}$ planes).

\section{Conclusion}

Stress corrosion behaviours of thin-foil specimens of nitrogen-rich austenitic stainless steel in a $3 \% \mathrm{NaCl}$ aqueous solution ( $\mathrm{pH} \mathrm{1.6)}$ at room temperature and of Inconel in a boiling $42 \% \mathrm{MgCl}_{2}$ aqueous solution are quite similar to that of nitrogen-rich austenitic stainless 
steel in a boiling $42 \% \mathrm{MgCl}_{2}$ aqueous solution.

According to observations of the stress corrosion of bulk specimens with varying exposure time by the replica method, at the initial stage of corrosion the corrosion behaviours are almost the same either in a condition susceptible or unsusceptible to transgranular cracking. With increasing exposure time, however, the corrosion of the alloys in a condition susceptible to cracking proceeds rapidly along slip planes into the interiors of the alloys, while the corrosion of the alloys in an unsusceptible condition remains in the region of slip steps as micro-attack and does not extend over into the interiors of the alloys.

Mechanisms of nucleation and propagation of trans- granular stress corrosion cracking in austenitic stainless steels are different from each other. That is, the nucleation of transgranular cracking requires that the dislocations have a planar distribution, and that the fresh slip steps are chemically active and the other region of the steel surface is covered with a stable surface film during deformation in a corrosive environment.

The segregation of solute atoms is necessary for the propagation of micro-attack nucleated on the slip steps into the interiors of alloys. In an alloy with high stress. corrosion susceptibility, the possibity of segregation at $200^{\circ} \mathrm{C}$ is observed by electron microscopy and in the measurement of the stress-strain relations. 